
$(N S N)$

\title{
Chronic Administration of Combined Oral Contraceptive Pill Causes Prefrontal Cortical Oxidative Stress in Female Wistar Rats
}

\author{
Bamidele S. Ajilore ${ }^{1}$, Olubukola S. Olorunnisola ${ }^{2}$, Tolulope O. Oluwadairo ${ }^{3}$, \\ Olumide S. Fadahunsi ${ }^{2}$, Peter I. Adegbola ${ }^{2}$
}

\begin{abstract}
${ }^{1}$ Department of Medical Biochemistry, Faculty of Basic Medical Sciences, Osun State University, Osogbo, Nigeria ${ }^{2}$ Department of Biochemistry, Faculty of Basic Medical Sciences, Ladoke Akintola University of Technology, Ogbomoso, Nigeria; ${ }^{3}$ Department of Biochemistry, Faculty of Basic and Applied Sciences, Osun State University, Osogbo, Nigeria
\end{abstract}

Received:

May 2021

Accepted: June 2021

\begin{abstract}
Combined oral contraceptive pill (COCP) is used by women to prevent ovulation. This study investigated toxicological effects of COCP on the brain of female rats. Fifteen rats were divided at random into three groups $(n=5)$ : Normal control, and first and second cycles treated orally with COCP $(0.04 \mu \mathrm{g} / \mathrm{kg}$ bwt of ethinyl oestradiol and $2 \mu \mathrm{g} / \mathrm{kg}$ bwt levonorgestrel) daily for 21 and 42 days respectively. Toxicological effect of treatment on the brain was assessed in the prefrontal cortical acetylcholinesterase, sodium/potassium-ATPase $\left(\mathrm{Na}^{+} / \mathrm{K}^{+}\right.$-ATPase), superoxide dismutase and catalase activities, lipid peroxidation and reduced glutathione levels. Histomorphological examination of the prefrontal cortex of the rats in all the groups was carried out. Activities of cortical $\mathrm{Na}^{+} / \mathrm{K}^{+}$-ATPase, acetylcholinesterase, superoxide dismutase and catalase were significantly $(p<0.05)$ reduced following chronic administration of COCP. Histomorphological study of the pre-frontal cortex showed large pyramidal neurons, pyknotic pyramidal neurons, condensed nuclei and increased perineural spaces. Results showed that chronic administration of oral contraceptive caused prefrontal cortical oxidative stress by repressing activities of antioxidant enzymes, $\mathrm{Na}^{+} / \mathrm{K}^{+}$-ATPase and acetylcholinesterase.
\end{abstract}

Key words: Oral contraceptive, Neurotoxicology, $\mathrm{Na}^{+} / \mathrm{K}^{+}-$ATPase, Acetylcholinesterase, Antioxidant enzymes, Neurodegeneration

\section{INTRODUCTION}

Oral contraceptive pills (OCP) are classified into three namely: combined oestrogen-progesterone, progesterone only and the continuous or extended use pill. The most prescribed contraceptive pills is combined (COCP) (Cooper and Mahdy, 2020). The progesterone in the COCP prevents pregnancy while the oestrogen component controls bleeding during menstruation (Baird and Glasier 1993). Prevention of pregnancy by progesterone is via negative feedback inhibition of the hypothalamus to slow the rate at which gonadotropin releasing hormone is produced, which in turn reduces secretion of follicle- stimulating and luteinizing hormones. The cumulative effect is the prevention of ovulation. On the other hand, oestrogen controls bleeding during menstruation via negative feedback inhibition of the anterior pituitary, which blocks development of follicles and decreases secretion of follicle- stimulating hormone (Cooper and Mahdy 2020).

Combined OCP (COCP) contains twenty-eight tablets. The first twenty-one-hormone containing beige coated tablets contain $0.003 \mathrm{mg}$ of ethinyl oestradiol and $0.15 \mathrm{mg}$ levonorgestrel, and the remaining seven tablets contain placebo. The hormone-containing pills are taken daily for the first

Correspondence: Bamidele S. Ajilore, PhD, Department of Medical Biochemistry, Faculty of Basic Medical Sciences, Osun State University, PMB 4494, Osogbo, Osun State, Nigeria.. doctorajibam@yahoo.com; Phone: +2347033985727 
21 days while the last 7 days of the cycle are hormone-free days (Callahan and Caughey 2013). Non-contraceptive indications of the hormonal pill are treatment of medical conditions like polycystic ovary syndrome, endometriosis, adenomyosis, acne, menorrhagia (Curtis et al. 2016).

Nausea, headache, abdominal cramping, breast tenderness, and increase in vaginal discharge or decreased libido are few of the side effects of oral contraceptive pills. Increased risk of venous thromboembolism and heart attack have also been reported (Weerasinghe et al. 2017). Whereas little or no attention is paid to the effects of the COCP on the brain despite being the site of action of the drug. In the present study, neurotoxicological assessment of the brain tissues from rats administered COCP was carried out.

\section{MATERIALS AND METHODS}

\section{Reagents and Chemicals}

Combined oral contraceptive pill was purchased from Bayer Pharma AG 13342 Berlin Germany. Acetylcholine iodide, sodium barbital, DTNB, sodium chloride, Tween20, hydrochloric acid, trisaminomethane, ethylene diamine- tetraacetic acid, ammonium molybdate, potassium chloride, magnesium chloride were purchased from either Sigma-Aldrich, U.S.A., or British Drug House (BDH) chemical Ltd., England. All reagents and chemicals used were of analytical grade.

\section{Experimental Design}

Fifteen female Wistar rats were obtained from the Osun State University Animal House. The protocol for this research project conformed to the provisions of the Declaration of Helsinki in 1995, as revised in Fortaleza, Brazil, October 2013 (World Medical Association 2013). All animal procedures in this study were performed according to the guidelines of the Faculty of Basic Medical Sciences Research and Ethics committee, LAUTECH for the use of laboratory animals with approval number LFBMSEC/28/2020.

The rats were kept in clean plastic cages littered with saw dust and provided with rat pellet, water ad libitum and maintained at room temperature of $25^{\circ} \mathrm{C}$, with 12 hour light/ dark cycle. The animals were acclimatized to standard laboratory conditions and randomly

Table 1: Markers of oxidative stress in the brain of control and COCP-treated groups

\begin{tabular}{ccccc}
\hline $\begin{array}{c}\text { Treatment } \\
\text { Group }\end{array}$ & $\begin{array}{c}\text { SOD (unit/mg } \\
\text { protein) }\end{array}$ & $\begin{array}{c}\text { Catalase } \\
\text { (unit/mg protein) }\end{array}$ & $\begin{array}{c}\text { GSH } \\
\text { (nmol/ml) }\end{array}$ & $\begin{array}{c}\text { TBARS } \\
\text { (nmol MDA/g tissue) }\end{array}$ \\
\hline Control & $1.36 \pm 0.23^{\mathrm{b}}$ & $2.44 \pm 1.09^{\mathrm{b}}$ & $0.28 \pm 0.06^{\mathrm{b}}$ & $1.78 \pm 0.21^{\mathrm{a}}$ \\
First cycle & $1.14 \pm 0.15^{\mathrm{ab}}$ & $2.04 \pm 0.84^{\mathrm{ab}}$ & $0.28 \pm 0.07^{\mathrm{b}}$ & $1.94 \pm 0.34^{\mathrm{a}}$ \\
Second cycle & $0.92 \pm 0.33^{\mathrm{a}}$ & $1.58 \pm 0.51^{\mathrm{a}}$ & $0.11 \pm 0.02^{\mathrm{a}}$ & $3.10 \pm 0.55^{\mathrm{b}}$ \\
\hline
\end{tabular}

Values are expressed as mean \pm S.D $(n=5)$. Means with different Duncan superscripts along the columns are statistically significant at $p<0.05$ divided into 3 groups $(n=5)$ as follows: Control, rats in this group were administered distilled water only (5 $\mathrm{ml} / \mathrm{kg})$; First cycle, rats in this group were treated orally with COCP $(0.04 \mu \mathrm{g} / \mathrm{kg}$ bwt of ethinyl oestradiol and $2 \mu \mathrm{g} / \mathrm{kg}$ body weight (bwt) levonorgestrel) daily for 21 days; Second cycle, rats in this group were treated orally with COCP $(0.04 \mu \mathrm{g} / \mathrm{kg}$ bwt of ethinyl oestradiol and $2 \mu \mathrm{g} / \mathrm{kg}$ bwt levonorgestrel) daily for 42 days.

All animals were sacrificed by cervical dislocation at the end of the treatment periods. The prefrontal cortex was harvested, cleaned and used for biochemical and histomorphological studies. Fresh brain harvested from each rat was homogenized (tissue: buffer /1:10) in cold $60 \mathrm{mM}$ Tris- $\mathrm{HCl}, \mathrm{pH} 7.4$ and centrifuged at $4000 \times \mathrm{g}$ for $10 \mathrm{~min}$ at $4{ }^{\circ} \mathrm{C}$ to obtain a clear supernatant.

\section{Determination of ATPase Activity}

Sodium/potassium-ATPase ( $\mathrm{Na}^{+} / \mathrm{K}^{+}$-ATPase) activity in the brain was evaluated as described by Ajilore et al. (2020). The specific $\mathrm{Na}^{+} / \mathrm{K}^{+}$-ATPase activity was obtained by subtracting the ouabain-insensitive activity from the activity in the absence of ouabain.

\section{Determination of Acetylcholinesterase Activity} Acetylcholinesterase activity in the brain was determined using the spectrophotometric method described by Ellman (1959).

\section{Determination of Thiobarbituric Acid Reactive Substances, Reduced Glutathione Levels,} Superoxide dismutase and Catalase Activities

The extent of lipid peroxidation in the brain was determined by measuring the production of thiobarbituric acid reactive substances (TBARS) using the procedure described by Ottolenghi (1959), and expressed as nanomolar of malondialdehyde $(\mathrm{MDA}) / \mathrm{g}$ tissue, while reduced glutathione (GSH) level was determined by the method described by Sapakal et al. (2008). Superoxide dismutase (SOD) activity was estimated according to the method described by Mccord and Fridovich (1969), while catalase activity was determined according to the method of Sinha et al. (1972). Tissue total protein level was determined according to the method described by Gornal et al. (1949) using the Randox diagnostic kit.

\section{Histomorphological Study}

Brain tissues were immediately fixed after harvest in $10 \%$ formalin and used for histomorphological study. The tissues were transferred into an automatic processor where they went through a process of 
dehydration. The tissues were then cleared in xylene and embedded in paraffin wax. Serial sections of 5 $\mu \mathrm{m}$ thickness were obtained using a rotary microtome. The tissue sections were deparaffinised, hydrated and stained using the routine haematoxylin and eosin and Cresyl fast violet staining methods. The stained sections were examined with a Leica DM750 microscope interfaced with Leica ICC 50 camera.

\section{Statistical Analysis}

Data obtained were analysed using one way analysis of variance (SPSS version 20.0). Levene statistic was used for tests of homogeneity of variance. Duncan was used for multiple comparisons and homogenous subsets and results considered to be statistically significant when $p$ values were less than 0.05 .

Table 2: Effects of combined oral contraceptive pill administration on cerebral sodium/potassium-ATPase and acetylcholinesterase activities

\begin{tabular}{ccc}
\hline $\begin{array}{c}\text { Treatment } \\
\text { Group }\end{array}$ & $\begin{array}{c}\mathrm{Na}^{+} / \mathrm{K}^{+}-\mathrm{ATPase}(\mu \mathrm{g} \mathrm{Pi} \\
\text { liberated } / \mathrm{min} / \mathrm{g} \text { protein })\end{array}$ & $\begin{array}{c}\mathrm{AChE} \\
(\mathrm{nmol} / \mathrm{min} / \mathrm{ml})\end{array}$ \\
\hline Control & $73.43 \pm 18.68^{\mathrm{b}}$ & $4.80 \pm 0.12^{\mathrm{b}}$ \\
First cycle & $47.43 \pm 15.78^{\mathrm{a}}$ & $4.62 \pm 0.16^{\mathrm{b}}$ \\
Second cycle & $46.53 \pm 8.37^{\mathrm{a}}$ & $4.04 \pm 0.21^{\mathrm{a}}$ \\
\hline
\end{tabular}

Values are expressed as mean \pm S.D $(n=5)$. Means with different Duncan superscripts along the columns are statistically significant at $p<0.05$

\section{RESULTS}

Effects of Combined Oral Contraceptive Pill Administration on Markers of Oxidative Stress in Brain

The effect of COCP on lipid peroxidation, reduced glutathione levels, superoxide dismutase and catalase activities in the brain following sub-chronic and chronic exposures of rats is as shown in Table 1 and Figure 1. The extent of cerebral lipid peroxidation (LPO) was assessed by measuring the levels of MDA, a TBARS in the prefrontal cortex. The level of TBARS was significantly $(p<0.05)$ increased at the end of the 2nd cycle treatment when compared with the levels in the control group. TBARS was also

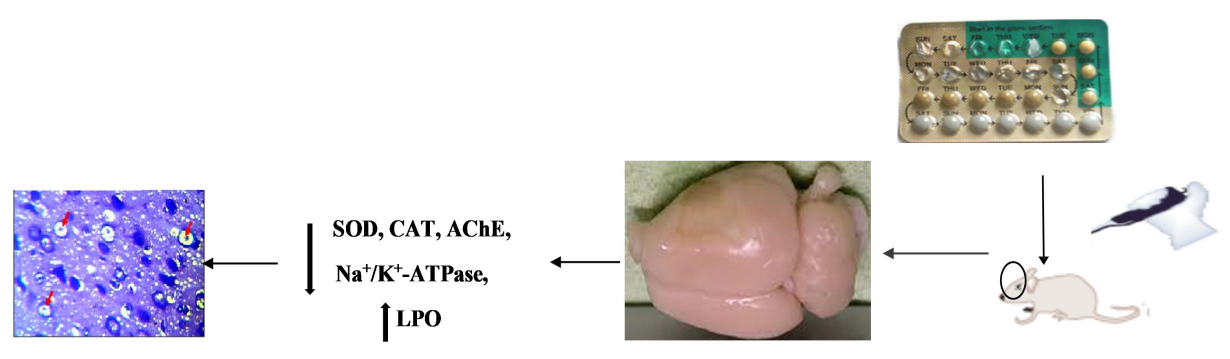

Fig. 1 Summarized effects of combined oral contraceptive pill on the brain of female rat. SOD: Superoxide dismutase, CAT: Catalase, AChE: Acetylcholinesterase, $\mathrm{Na}+\mathrm{K}+-\mathrm{ATP}$ ase: Sodium/potassium-ATPase, LPO: Lipid peroxidation. increased at the end of first cycle treatment (but not significant). There was no significant difference observed in GSH at the end of the 1st cycle treatment, but the level of GSH was significantly $(p<0.05)$ reduced at the end of the 2nd cycle treatment when compared to the levels observed in the control and 1st cycle rats. Activities of both SOD and catalase were significantly $(p<0.05)$ repressed in the two treatment groups (2nd cycle < 1st cycle) when compared to the levels of the two enzymes in the control rats.

Effects of Combined Oral Contraceptive Pill Administration on the Brain Sodium/PotassiumATPase and Acetylcholinesterase Activities

The effects of COOP on the activities of $\mathrm{Na}^{+} / \mathrm{K}^{+}$ATPase and acetylcholinesterase (AChE) enzymes in the prefrontal cortex is as shown in Table 2 and Figure 1. Cerebral $\mathrm{Na}^{+} / \mathrm{K}^{+}$-ATPase and AChE activities were significantly $(p<0.05)$ repressed in the two treatment groups when compared to the activities in the normal control group

Histomorphology of Prefrontal Cortex of the Rats Administered Combined Oral Contraceptive Pill

The representative micrographs of cresyl fast violet and haematoxylin and eosin stains of the cytoarchitecture of the prefrontal cortex (PFC) are as shown in Figures 2 and 3 respectively. Normal histological features of the PFC in the control as well as near normal histological features were observed in the first cycle groups. These features were large pyramidal neurons with long axons that extend well from the soma to adjacent neurons within the neuropil; apical and basal dendrites extended from the well delineated soma of the pyramidal neurons in both groups. Second cycle treatment caused degenerative changes in the PFC that was characterized by clustered pyknotic pyramidal neurons that appear with fragmented cytoplasm and condensed nuclei within soma (red arrow). Perineural spaces were seen surrounding degenerating neurons (red arrows). Axons and dendrites were scarcely appreciable around neurons in this group.

\section{DISCUSSION}

The toxicological effect of oral contraceptives on the brain was assessed following subchronic and chronic exposures of rats to COCP. The extent of lipid peroxidation (LPO) in the brain was evaluated by measuring the levels of MDA, a 
TBARS. Significant increase in the level of LPO in the rats was due to generation of reactive oxygen species (ROS). MDA is one of the aldehydes formed from peroxidation of lipids due to attack of polyunsaturated fatty acids in the cell membrane by ROS (Taso et al. 2019). Oxidative stress occurs when prooxidant is more than antioxidant. Chronic administration of COCP generated ROS which subsequently increased the level of MDA in the prefrontal cortex. This TBAR is also a mutagenic product of LPO and its increased level in the brain has been previously reported in the development of neurodegenerative diseases like Alzheimer's and Parkinson (Reed 2011; Pizzimenti et al. 2013; Taso et al. 2019).

Glutathione is easily converted to its oxidized form when there is oxidative stress. Most of the glutathione in the brain is in the reduced form (GSH). Ability to neutralize ROS is lesser when compared with that of the liver or the kidney because the brain has lesser superoxide dismutase, catalase, and glutathione peroxidase activities. As a result of this, detoxification of ROS in the brain is solely dependent on glutathione, thereby its reduced level in the brain (Dringen 2000). Significant reduction in the glutathione level observed in the 2nd treatment group might be responsible for resultant increase in the degree of lipid peroxidation seen in the two groups. Deficiency of glutathione in the brain has been reported to be an important factor in the pathogenesis of neurodegenerative diseases (Dringen 2000).
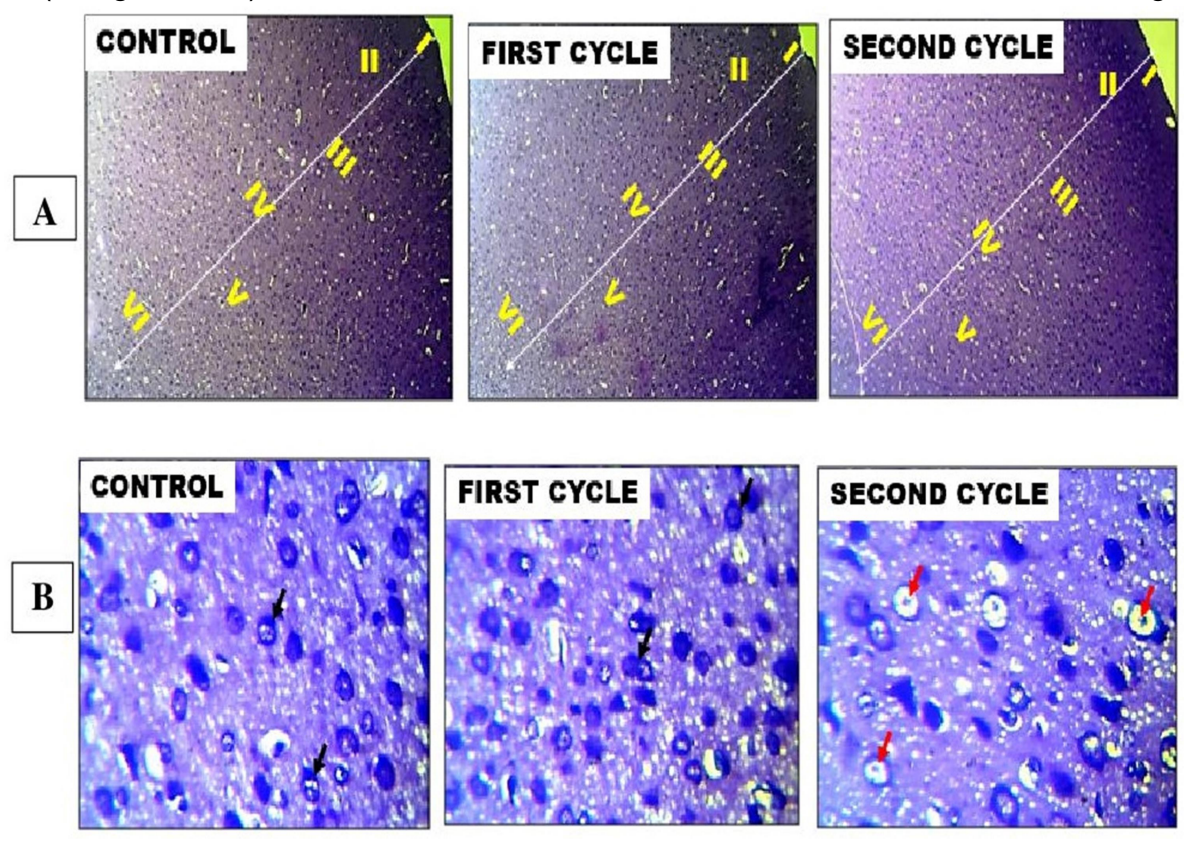

Fig. 2: Representative photomicrographs of the histomorphology of the prefrontal cortex in Wistar rats. The molecular layer (I), External granular layer (II), External pyramidal layer (III), Internal granular layer (IV), Internal pyramidal layer (V) and the multiform layer (VI) are demonstrated across study groups. Pyramidal neurons (black arrow). Condensed nuclei within soma (red arrow). Cresyl fast violet stain $(A=\times 40, B=\times 400)$.
Superoxide dismutase (SOD) and catalase enzymes are essential protective mechanisms against free radical induced tissue damage. While SOD converts superoxide radical to hydrogen peroxide, catalase converts hydrogen peroxide to water. Repression in the activities of the two enzymes could be used to explain increased level of lipid peroxidation in the two treatment groups. Reduced SOD and catalase activities have been reported as the causative factors in the pathophysiology of aging, cancer and neurodegenerative diseases (Nandi et al. 2019).

The pattern of decrease in $\mathrm{Na}^{+} / \mathrm{K}^{+}$-ATPase and AChE activities in the prefrontal cortex following administration of COCP is duration-dependent (2nd cycle < 1st cycle). $\mathrm{Na}^{+} / \mathrm{K}^{+}$-ATPase is responsible for the generation of normal resting membrane potential and diverse cellular activities (Arnaiz 2007). Reduced $\mathrm{Na}^{+} / \mathrm{K}^{+}$-ATPase activity has been previously observed in pathological states like hypoglycaemia, ischemia, epilepsy, Parkinson disease, depression and schizophrenia (Gamaro et al. 2003; Arnaiz 2007). On the other hand, AChE is an important enzyme of the cholinergic nervous system. Loss of cholinergic neurons in the forebrain is responsible for the associated decrease in the level of acetylcholine and AChE activity which are biochemical features of Alzheimer's disease (Kaduszkiewicz et al. 2005; Arnaiz 2007). Reduced activities of $\mathrm{Na}^{+} / \mathrm{K}^{+}$-ATPase and AChE in chronic administration of COCP in this study could be due to increased lipid peroxidation and impaired enzymatic antioxidant defense system in the treatment groups since central nervous system is one of the major targets of lipid peroxidation and its products.

\section{Conclusion}

Chronic administration of COOP causes prefrontal cortical oxidative stress and perturbed cholinergic transmission by repressing activities of superoxide oxide dismutase, catalase, $\mathrm{Na}^{+} / \mathrm{K}^{+}$-ATPase and $\mathrm{ACHE}$ enzymes and increasing degree of lipid peroxidation.

\section{Conflict of Interest \\ None declared.}

\section{Author Contributions}

All the authors conceived and designed the study. ABS and OTO conducted the research, provided research materials and collected the data. OOS, $A P I$ and FOS organized the data. $A B S$ and OOS analysed and interpreted the data. ABS 
wrote initial and final draft of the manuscript, while OOS, OTO, API and FOS provided logistic supports.

\section{REFERENCES}

Ajilore, B.S., Agboola, T.M., Ayalomhe, I.A. and Oluwadairo, T.O. (2020) Modulatory effects of tetracarpidium conophorum seed phenolic extract on
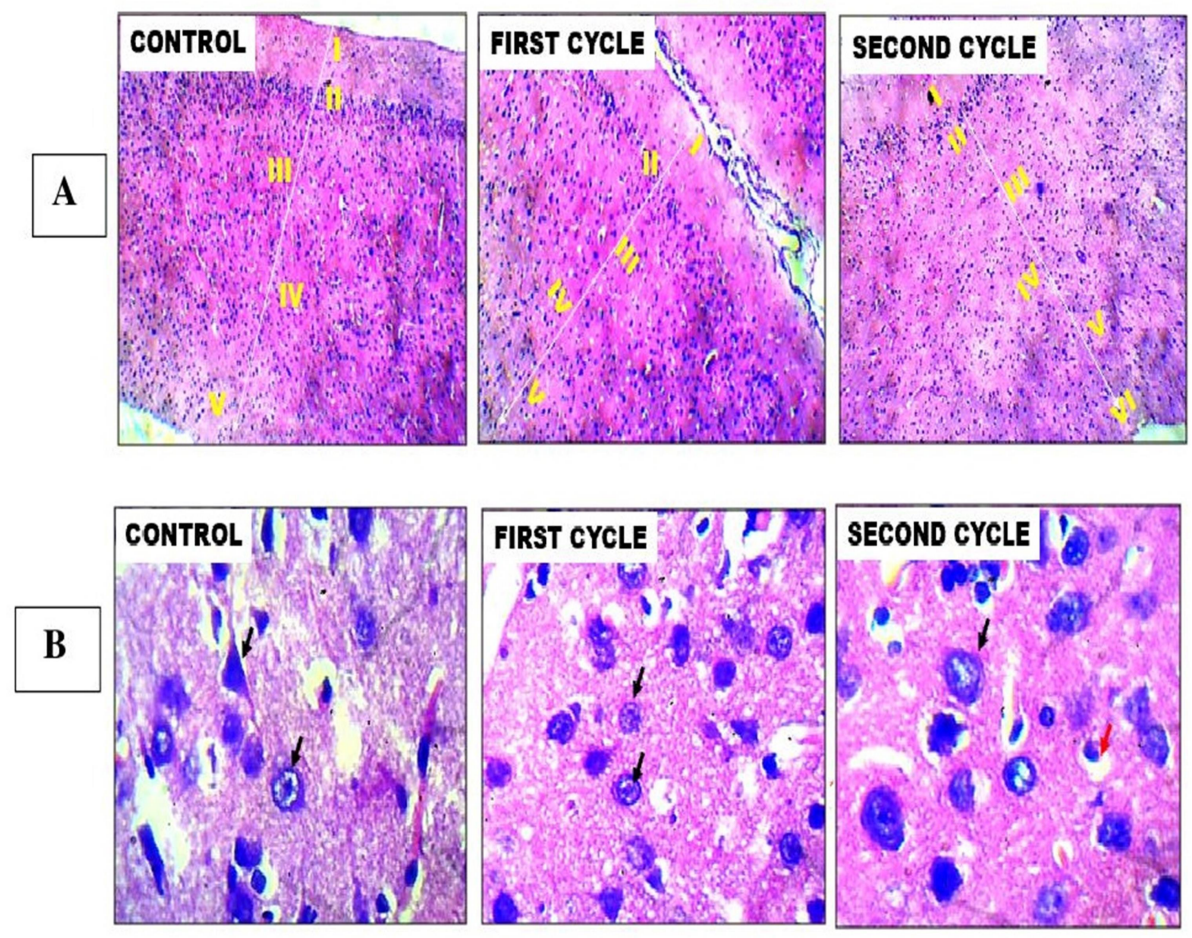

Fig. 3: Representative photomicrographs of the histomorphology of the prefrontal cortex in Wistar rats. The molecular layer (I), External granular layer (II), External pyramidal layer (III), Internal granular layer (IV), Internal pyramidal layer (V) and the multiform layer (VI) are demonstrated across study groups. Pyramidal neurons (black arrow). Perineural spaces surrounding degenerating neurons (red arrows). Haematoxvlin and Eosin stain $(A=\times 40 . B=\times 400)$.

activities of selected enzymes of cardiovascular and neurological relevance. Ann Clin Exp Med. 1(2):118125.

Arnaiz, G.R. (2007) Na+, K+-ATPase in the brain: Structure and function. In: Lajtha, A., Reith, M.E.A. (eds). Handbook of Neurochemistry and Molecular Neurobiology. Springer, Boston.

Baird, D.T. and Glasier, A.F. (1993) Hormonal contraception. N Engl J Med. 328(21):1543-1549.

Callahan, T.L. and Caughey, A.B. (2013) Blueprints of Obstetrics \& Gynecology (6th ed.). Baltimore, MD: Lippincott Williams \& Wilkins.

Cooper, D.B. and Mahdy, H. (2020) Oral contraceptive pills. In: Stat Pearls [Internet]. Treasure Island (FL): Stat Pearls Publishing.

Curtis, K.M., Tepper, N.K., Jatlaoui, T.C., BerryBibee. E., Horton, L.G., Zapata, L.B. et al (2016) Medical eligibility criteria for contraceptive use, 2016. MMWR Recomm Rep. 65(3):1-103.
Dringen, R. (2000) Metabolism and functions of glutathione in brain. Prog Neurobiol. 62: 649-671.

Ellman, G.L. (1959) Tissue sulfhydryl groups. Arch Biochem Biophys. 82(1):70-77.

Gamaro, G.D., Streck, E.L., Matte, C., Prediger, M.E. and Wyse, A.T. (2003) Reduction of hippocampal $\mathrm{Na}+, \mathrm{K}+$-ATPase activity in rats subjected to an experimental model of depression. Neurochem Res.

\section{8:1339-1344.}

Gornal, A.G., Bardawill, C.J. and David, M.M. (1949) Determination of serum proteins by means of the biuret reaction. J Biol Chem. 177:751-766.

Kaduszkiewicz, $\quad \mathrm{H}$., Zimmermann, T., BeckBornholdt, H. P. and van den Bussche, H. (2005) Cholinesterase inhibitors for patients with Alzheimer's disease: systematic review of randomised clinical trials. BMJ. 331:321-327.

McCord, J.M. and Fridovich, I. (1969) Superoxide dismutase. An enzymic function for erythrocuprein (hemocuprein). J Biol Chem. 244: 6049-6055.

Nandi, A., Yan, L., Jana, C.K. and Das, N. (2019) Role of catalase in oxidative stress- and age-associated degenerative diseases. Oxidative Medicine and Cellular Longevity. 2019:119.

Ottolenghi, A. (1959) Interaction of ascorbic acid and mitochondria lipids. Arch Biochem Biophys. 79:355-363.

Pizzimenti, S., Ciamporcero, E., Daga, M., Pettazzoni, P., Arcaro, A., Cetrangolo, G. et al (2013) Interaction of aldehydes derived from lipid peroxidation and membrane proteins. Front Physiol 4:242.

Reed, T.T. (2011) Lipid peroxidation and neurodegenerative disease. Free Radical Biol Med. 51:1302-1319.

Sapakal, V.D., Shikalgar, T.S., Ghadge, R.V., Adnaik, R.S., Naikwade, N.S., Magdum, C.S. (2008) In vivo screening of antioxidant profile: a review. J Herbal Med Toxicol. 2: 1-8.

Sinha, A.K. (1972) Colorimetric assay of catalase. Anal Biochem. 47:389-94.

Taso, O.V., Philippou, A., Moustogiannis, A., Zevolis, E. and Koutsilieris, M. (2019) Lipid peroxidation 
products and their role in neurodegenerative diseases. Ann Res Hosp. 3:2.

Weerasinghe, M., Konradsen, F., Eddleston, M., Pearson, M., Agampodi, T., Storm, F. et al (2017) Overdose of oral contraceptive pills as a means of intentional selfpoisoning amongst young women in
Sri Lanka: considerations for family planning. J Fam Plann Reprod Health Care. 43(2):147-150.

World Medical Association (2013) Declaration of Helsinki ethical principles for medical research involving human subjects. JAMA. 310:20.

Cite as Ajilore, B.S., Olorunnisola, O.S., Oluwadairo, T.O., Fadahunsi, O.S. and Adegbola, P.I. (2021) Chronic administration of combined oral contraceptive pill causes prefrontal cortical oxidative stress in female Wistar rats. Nig. J. Neurosci. 12(2):50-55. http://doi.org/10.47081/njn2021.12.2/002

(C) Copyright Nigerian Journal of Neuroscience. All rights reserved. 